\title{
Noble Rats Display Decreased Weight Gain and Visceral Adiposity via Lifelong Exposure to an Isoflavone-Rich Diet
}

\author{
Edwin D. Lephart* \\ Department of Physiology \& Developmental Biology/Neuroscience, Brigham Young University, USA
}

Received: December 21, 2013; Accepted: January 30, 2014; Published: February 17, 2014

*Corresponding author: Edwin D. Lephart, Department of Physiology \& Developmental Biology/Neuroscience, Brigham Young University, Provo, UT 84602, USA, Tel: 801-422-8970; Fax: 801-422-0700; E-mail: Edwin_Lephart@byu.edu

\begin{abstract}
Obesity and cancer represent two of the greatest public health concerns. The relationship between obesity and cancer suggests an important role for visceral adipose tissue (VAT) versus generalized body fat. Male and female Noble rats develop a relatively high incidence of spontaneous and hormone-induced carcinomas. The main purpose of this study was to make an initial assessment of whether a high soy-isoflavonoid diet could decrease VAT and reduce overall body weight gain in Noble rats. The male and female rats were exposed solely to either a high soy-isoflavonoid diet (High-Iso) or a low-isoflavonoid diet (Low-Iso) from conception to adulthood. At the end of the experiment, at 145 days of age, overall weight gain and visceral fat deposition were recorded along with quantification of serum isoflavone levels (genistein, daidzein and equol). Serum isoflavone levels in the High-Iso treatment groups were significantly higher (by approximately 15-fold) compared to animals in the LowIso diet groups. Male and female Nobel rats fed the High-Iso diet displayed significantly lower body weight gain (by approximately $10 \%)$ compared to animals fed the Low-Iso diet. Notably, VAT deposition was reduced by $61 \%$ in females but $21 \%$ in males fed the High-Iso diet versus the Low-Iso diet. In summary, consumption of a diet high in isoflavones significantly lowered body weight and VAT deposition and a hypothesis may be proposed as to how soy-derived isoflavones may decrease VAT storage areas to potentially improve obesity and cancer outcomes.
\end{abstract}

Keywords: Isoflavones; Diet; Weight gain; Visceral fat; Noble rat; Cancer outcome

\section{Introduction}

Noble Rats Display Decreased Weight Gain and Visceral Adiposity via Lifelong Exposure to an Isoflavone-Rich Diet. The World Health Organization defines obesity as an abnormal or excessive fat accumulation in adipose tissue, to the extent that health is impaired (Obesity-Report WHO consultation, 2000) [1]. Obesity frequency has been steadily increasing over the past decades and in 2007-2008, the prevalence of obesity among US adults was $33.8 \%$ and for overweight individuals 68\% [2]. Furthermore, obesity is associated with the development and progression of various cancers, including tumors of the colon, esophagus, pancreas, liver, breast, prostate, kidney, endometrium and cardiovascular disease [3-7]. In fact, visceral rather than generalized body fat appears to play a key role between obesity being link to cancer [6,8]. Many biomarkers, hormones and chemical signals are involved in body weight gain, adipose tissue deposition and cancer outcomes [9,10]. For example, obesity in postmenopausal women has been associated with a higher risk of breast cancer that is linked to estrogen formation within the breast $[11,12]$. Also, obesity is associated with decreased testosterone levels in males [13]. This suggests a complex interaction between adipokines, inflammatory factors, hormones and other chemical signaling that is just beginning to be revealed.

One approach to investigate the causes of obesity and chronic disease is to examine the evidence for the discordance between modern diets and the evolution of consumption in humankind. In Martin C, et al. [14] summary article such a proposition is reviewed and the authors provide support for the consumption of plant foods as a way to reduce the risk of chronic disease. Such plant food molecules include polyphenolic compounds like the isoflavonoids [14], and there are several studies that suggest isoflavones prevent certain disorders such as breast and prostate cancer and cardiovascular disease [14-17]. However, Western diets generally have a 100-fold lower level of isoflavonids compared to Asian diets [14].

Notably, several studies from our laboratory have demonstrated that soy diets containing high levels of isoflavonoid compounds have positive influences on obesity, metabolism and prostate health [18-21]. Specifically, body weight and visceral adipose tissue (VAT) deposition parameters were significantly decreased in animals fed an isoflavone-rich diet compared to controls, most likely due to the selective estrogen receptor modulatory (SERM) actions of the isoflavonoid molecules.

However, the Noble rat model has not been studied in this regard as far as body weight and VAT deposition parameters via dietary treatments. The Noble rat model has been used to study spontaneous and hormonal (estrogen- and androgen-induced) carcinogenesis of mammary and prostate/seminal glands [2225].

The purpose of this study was to determine whether an isoflavonoid-rich diet derived from soy ingredients (with 600 
ppm or the High-Iso diet) compared to a low isoflavonoid diet (with 15 ppm or the Low-Iso diet) can influence body weight and VAT deposition when male or female rats were exposed to the treatments from conception to adulthood. In brief, body weight and VAT deposition were significantly lower in the High-Iso vs. the Low-Iso fed animals where female Noble rats displayed the greatest influence of the diet treatments.

\section{Methods}

\section{Animals and housing}

All procedures involving animals were approved by the Brigham Young University Institutional Animal Care and Use Committee. Fifty to fifty-five day old male and female Noble rats ( $\mathrm{n}=4$ by sex) were obtained through the Animal Production Program of the National Cancer Institute (NCI; Ferderick, MD, USA). The animals were placed on a $12 \mathrm{hr}$ light/dark schedule ( 6 am to $6 \mathrm{pm}$ ) and allowed ad libitum access to food (see diet treatments) and tap water. The animals stayed on the diet treatments by sex until approximately 90 days old when mating took place as outline below.

All animals were housed in clear plastic cages with wire lids $(20 \mathrm{~cm} \times 24 \mathrm{~cm} \times 40 \mathrm{~cm}$ standard shoebox with woodchip bedding). The young adult male and female rats were housed individually except during mating. Following delivery, offspring pups were housed with their mothers until age 21 days, at which point they were weaned and placed in separate cages (three to four animals per cage by sex by diet treatment). At 40 days the animals were separated to two animals per cage and finally, at 60 days, placed in individual cages by diet treatment.

\section{Mating}

Animals were diet-matched and mated to ensure offspring would be exposed solely to only one of the two diet treatments. During the mating procedure, males were housed within hanging wire cages over cardboard mats. One female was introduced into each male cage, and the cardboard was checked for the appearance of vaginal plugs twice a day (at about 8 a.m. and 5 p.m.) indicating successful mating/insemination. Inseminated females were removed from the male's cage, weighed and replaced with another female. This continued until vaginal plugs were found for all females. All males were fertile and inseminated 4 litters by diet treatment. Pregnancy was confirmed by a 30-40 g weight gain over the first 5-7 days of gestation.

\section{Diet treatments}

After arrival at our animal facilities, male and female rats to be mated were immediately placed on either a high soy-isoflavonoid diet (High-Iso) containing isoflavones at a concentration of approximately $600 \mathrm{ppm}$ as glycones and aglycones (Harlan Teklad 8604, Madison, WI, USA) or a low-isoflavonoid diet (LowIso) with approximately $15 \mathrm{ppm}$ of soy isoflavones as glycones (Zeigler Bros. Inc., Gardners, PA, USA, Phytoestrogen Reduced Rodent Diet) [26]. The Low-Iso diet contains casein and corn and wheat provided the protein content for this formulation [26]. Offspring were kept on the maternal diet, thus ensuring strict exposure to only one diet treatment from conception to adulthood. The specific nutritional content for these diets is described elsewhere [26]. The diets were balanced and matched for protein, fat, carbohydrate, amino acids, vitamins and minerals (Table 1).

Table 1: Composition of High Soy-Isoflavonoid (High-Iso) diet or a LowIsoflavonoid (Low-Iso) diet fed to noble rats.

\begin{tabular}{|c|c|c|}
\hline \multicolumn{2}{|c|}{ High-Iso } & Low-Iso \\
\hline Top 10 ingredients by weight & \multicolumn{1}{c|}{} \\
\hline 1 & Dehulled soybean meal & Ground corn \\
\hline 2 & Wheat middling & Ground wheat \\
\hline 3 & Flaked corn & Fish meal \\
\hline 4 & Ground corn & Wheat middling \\
\hline 5 & Fish meal & Lactic casein \\
\hline 6 & Cane molasses & Dried skin milk \\
\hline 7 & Ground wheat & Corn gluten meal \\
\hline 8 & Dried whey & Corn oil \\
\hline 9 & Soybean oil & $\begin{array}{c}\text { Brewers dried } \\
\text { yeast }\end{array}$ \\
\hline 10 & Brewers dried yeast & Dry molasses \\
\hline
\end{tabular}

Proximate composition of the diets

\begin{tabular}{|c|c|c|}
\hline Protein (g/kg) & 243 & 235 \\
\hline Fat (g/kg) & 47 & 53 \\
\hline Carbohydrate (g/kg) & 402 & 513 \\
\hline Crude fiber (g/kg) & 40 & 25 \\
\hline $\begin{array}{c}\text { Neutral detergent fiber } \\
\text { (g/kg) }\end{array}$ & 124 & 67 \\
\hline Ash (g/kg) & 74.0 & 64.5 \\
\hline $\begin{array}{c}\text { Genistein + Daidzein } \\
(\mathrm{g} / \mathrm{kg})\end{array}$ & 0.62 & 0.01 \\
\hline Energy density (kJ/kg) & 12,560 & 14,528 \\
\hline $\begin{array}{c}\text { Energy from protein } \\
(\%)\end{array}$ & 32 & 14 \\
\hline Energy from fat (\%) & 14 & 59 \\
\hline $\begin{array}{c}\text { Energy from } \\
\text { carbohydrates }(\%)\end{array}$ & 54 & 27 \\
\hline Amino Acids (g/kg) & & 14 \\
\hline
\end{tabular}

\begin{tabular}{|c|c|c|}
\hline Amino Acids (g/kg) & \multicolumn{2}{|c|}{} \\
\hline Arginine & 15.3 & 11.3 \\
\hline Cystine & 3.7 & 2.7 \\
\hline Histidine & 5.8 & 5.9 \\
\hline Isoleucine & 10.0 & 11.7 \\
\hline Leucine & 19.0 & 21.6 \\
\hline Lysine & 14.0 & 14.2 \\
\hline Methionine & 4.2 & 5.9 \\
\hline Phenylalanine+tyrosine & 20.0 & 20.7 \\
\hline Threonine & 9.4 & 9.4 \\
\hline Tryptophan & 2.9 & 2.5 \\
\hline Valine & 11.0 & 13.6 \\
\hline Minerals (mg/kg) & & \\
\hline Calcium & 14,000 & 12,000 \\
\hline Chloride & 5,000 & 4,300 \\
\hline Cobalt & 0.71 & 0.52 \\
\hline Copper & 25 & 13 \\
\hline Iodine & 2 & 1.84 \\
\hline
\end{tabular}




\begin{tabular}{|c|c|c|}
\hline Iron & 300 & 245 \\
\hline Magnesium & 3,000 & 1,500 \\
\hline Manganese & 100 & 96 \\
\hline Phosphorus & 11,000 & 9,500 \\
\hline Potassium & 10,000 & 5,500 \\
\hline $\mathrm{Se}$ & 0.34 & 0.45 \\
\hline Sodium & 3,000 & 3,000 \\
\hline Zinc & 80 & 60 \\
\hline \multicolumn{3}{|l|}{ Vitamins (mg/kg) } \\
\hline Biotin & 0.38 & 0.37 \\
\hline Cholecalciferol & 0.060 & 0.126 \\
\hline Choline & 2,530 & 1,646 \\
\hline Folate & 3 & 3 \\
\hline Menadione & 40 & 31 \\
\hline Niacin & 63 & 76.5 \\
\hline Pantothenic acid & 21 & 31.7 \\
\hline Riboflavin & 8 & 7 \\
\hline Thiamin & 27 & 17.3 \\
\hline Vitamin A & 3.78 & 1.98 \\
\hline Vitamin B-6 & 13 & 10 \\
\hline Vitamin B-12 & 0.050 & 0.048 \\
\hline Vitamin E & 54 & 22 \\
\hline \multicolumn{3}{|l|}{ Linoleic acid (mg/kg) } \\
\hline Linoleic acid & 18.7 & 22.8 \\
\hline
\end{tabular}

\section{Body weight gain, visceral adipose tissue weight and} blood sample collection

Tissue collection occurred at 145 days of age. Animals $(n=8-$ to-10) by diet treatment by sex (representing 4 litters) were weighed $( \pm 0.1$ grams). To determine final body weight gained each animal's birth weight was subtracted from their body weight at 145 days of age. Then the animals were anesthetized (ketamine/acepromazine at $75 / 2.5 \mathrm{mg} / \mathrm{kg}$ IP) prior to collecting blood samples and VAT. An incision was made from the pelvis to the bottom of the rib cage after which arterial blood was collected from the heart. Subsequently, white adipose tissue (or VAT) was dissected from the caudal surface of the diaphragm to the base of the pelvic cavity and recorded in grams $( \pm 0.01$ grams) for each animal.

\section{Determination of isoflavone blood levels}

After an arterial blood sample $(5-7 \mathrm{ml})$ was collected from each animal, the sample was allowed to clot and then centrifuged to obtain serum, which was then labeled and frozen at $-20^{\circ} \mathrm{C}$ until analysis was performed. Quantification of total isoflavonoid (daidzein, genistein, and equol) serum levels were performed at ESA Biosciences, Inc. Chelmford, MA, USA, using HPLCelectrochemical detection (ECD) with a lower limit of detection of $5 \mathrm{ng} / \mathrm{ml}$ for each aglycone. Samples (by diet treatment and sex) were analyzed in duplicate in a single assay along with internal control samples; the intra-assay coefficient of variation was approximately $4 \%$.

\section{Statistical analysis}

All data sets were analyzed with Minitab (State College,
PA, USA) software [by ANOVA (unstacked data)], followed by Fisher's pairwise comparisons to determine significance and all data were expressed as the mean \pm standard error of the mean (SEM); $\mathrm{p}<0.05$ was considered significant.

\section{Results and Discussion}

\section{Serum isoflavone levels}

Serum isoflavone levels in males and females fed the High-Iso diet were significantly higher compared to animals fed the LowIso diet (Figure 1). For example, total isoflavone levels in female Noble rats fed the High-Iso diet were approximately 16.8-fold higher compared to the Low-Iso values $(\mathrm{p}<0.001)$. Additionally, the total isoflavone levels in male Noble rats fed the High-Iso diet were approximately 13.9-fold higher compared to the Low-Iso values $(p<0.001$, Figure 1$)$. Equol represented the majority of the total isoflavone values:

a) In females, equol represented $77 \%$ of the total isoflavone values followed by daidzein (15\%), then genistein (8\%), and,

b) In males, equol represented $72 \%$ of the total isoflavone values followed by daidzein (21\%) then genistein (7\%).

The present data confirm that rodents, in general, produce high circulating levels of the polyphenolic molecule, equol when fed a soy-containing diet $[27,28]$.

The present total isoflavone results by diet treatments were similar to those reported elsewhere for male Long-Evans rats (@ 75 or 100 days old) fed the same diets [20,29]. However, male Noble rat total isoflavone values in the present study fed the

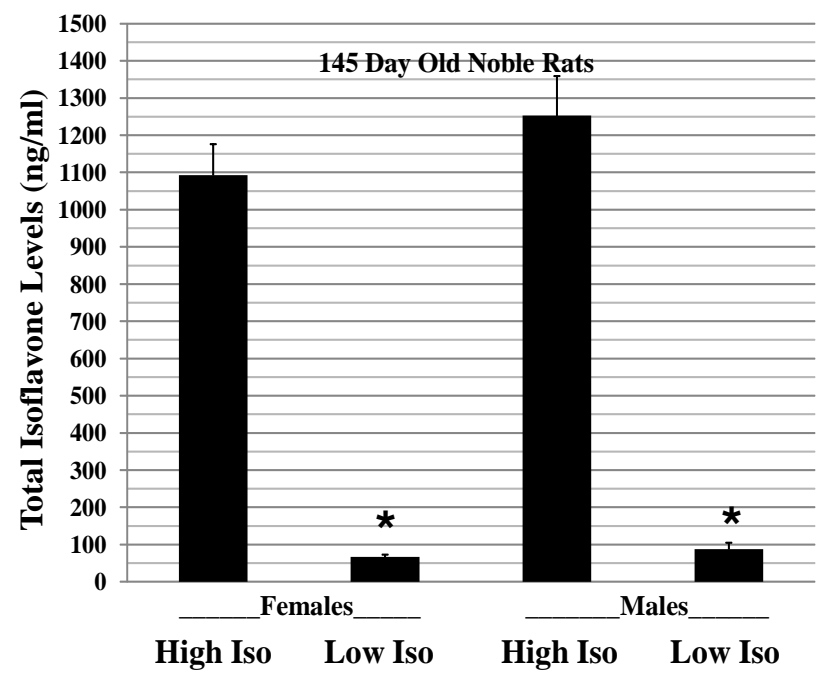

Figure 1: Total circulating serum Isoflavone levels $(\mathrm{ng} / \mathrm{ml})$ by sex and diet treatment in noble rats. Isoflavones analysis was performed by HPLC-EC. Symbol $(*)$ : significantly lower total Isoflavone levels $(\mathrm{p}<0.001)$ in animals fed the Low-Iso diet (containing approximately $15 \mathrm{ppm}$ ) versus animals fed the High-Iso diet (containing approximately $600 \mathrm{ppm}$ of glycones and agylcones). In general, equol represented $77 \%$ of the total Isoflavone values followed by Daidzein $(15 \%)$ then Genistein $(8 \%)$ in female and in males equol represented $72 \%$ of the total Isoflavone values followed by Daidzein (21\%) then Genistein (7\%). 
High-Iso diet were approximately 25 to $30 \%$ lower compared to male Long-Evans rats on the same High-Iso diet $[20,29]$. This may suggest a difference in isoflavone metabolism and/or clearance between the two rat strains or potential differences in agerelated parameters. Also, the equol metabolite represented $73 \%$ of the total isoflavones in the present study from male Noble rats fed the High-Iso diet which were similar to those reported for adult male Long-Evans rats on the same diet at $77 \%$ for 75 day old or $82 \%$ for 100 day old animals [20,29].

\section{Body weight gain and VAT weight}

Male and female Nobel rats fed the High-Iso diet displayed significantly lower body weight gain compared to animals fed the Low-Iso diet $(\mathrm{p}<0.042$ and $\mathrm{p}<0.038$, respectively; Figures $2 \&$ $3)$. The reduction in body weight gain was greater in the female Noble rats at approximately $13 \%$ while in male Noble rats the decrease was approximately $8 \%$ in the High-Iso groups compared to animals fed the Low-Iso diet. The present results were similar to previous studies examining young adult and aging (300 day old) Long-Evans rats for decreased body weight gain using the same two diet treatments $[20,29]$.

When VAT weight was examined, VAT deposition was significantly reduced by $61 \%$ in females (from approximately 5.4 to 2.1 grams; $\mathrm{p}<0.011$ ) and $21 \%$ in males (from approximately 3.9 to 3.1 grams; $(\mathrm{p}<0.027)$ fed the High-Iso diet versus the Low-Iso diet (Figures $4 \& 5$ ). The present results were similar to previous findings where feeding Long-Evans rats significantly reduced VAT weights when fed a High-Iso vs. a Low-Iso diet $[20,29]$. While genistein has been shown to have weight reducing and diabetic protecting properties [30], it is interesting to note that equol represents the major circulating isoflavonoid in the present study that has been shown to have beneficial weight and VAT reducing actions [19,31].

In the present study, the greater VAT deposition in females compared to males, in general, suggests that estrogens play an important role in promoting adipose tissue deposition. For

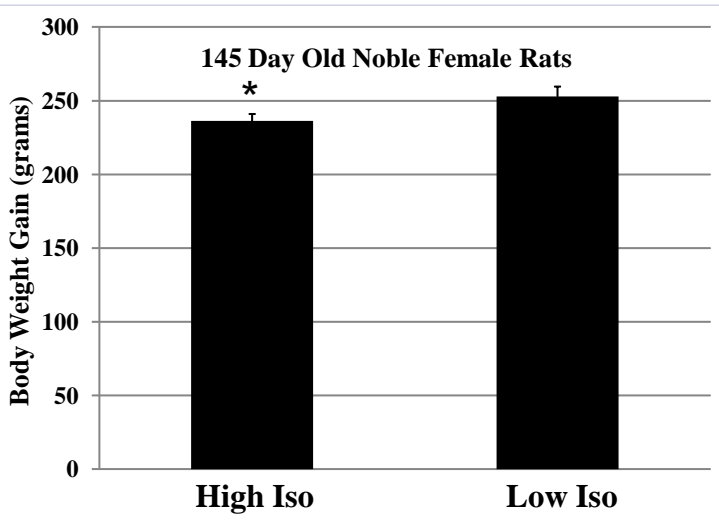

Figure 2: High Isoflavone (High-Iso) versus Low Isoflavone (Low-Iso) lifelong dietary consumption in female noble Rats: influence on body weight gain. Symbol $\left({ }^{*}\right)$ : significantly lower body weight gain from birth to adulthood in animals fed the High-Iso diet versus animals fed the Low-Iso diet $(\mathrm{p}<0.038)$.

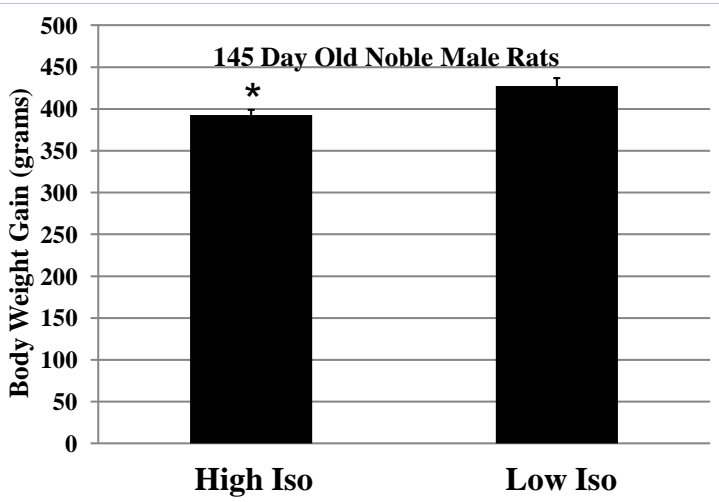

Figure 3: High Isoflavone (High-Iso) versus Low Isoflavone (Low-Iso) lifelong dietary consumption in male noble rats: influence on body weight gain. Symbol $(*)$ : significantly lower body weight gain from birth to adulthood in animals fed the High-Iso diet versus animals fed the Low-Iso diet $(\mathrm{p}<0.042)$.

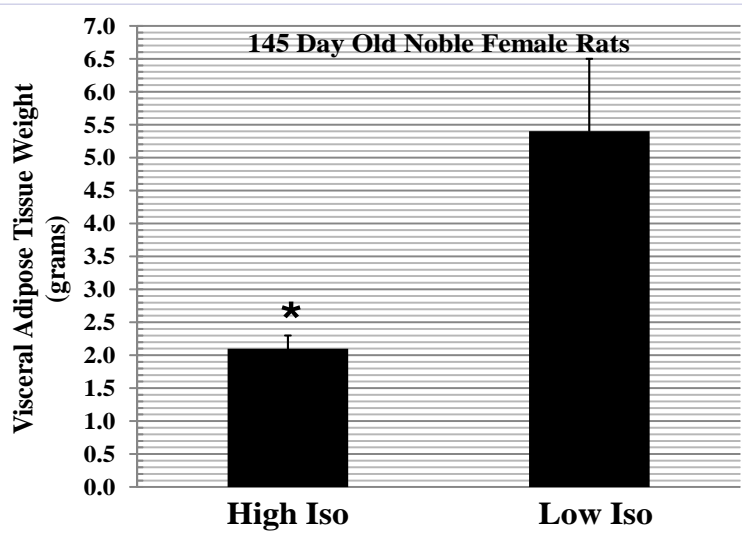

Figure 4: High Isoflavone (High-Iso) versus Low Isoflavone (Low-Iso) lifelong dietary consumption in female noble Rats: influence on visceral adipose deposition. Symbol $\left({ }^{*}\right)$ : significantly lower visceral adipose tissue weight $(\mathrm{p}<0.011)$ in adulthood of animals fed the High-Iso diet versus animals fed the Low-Iso diet.

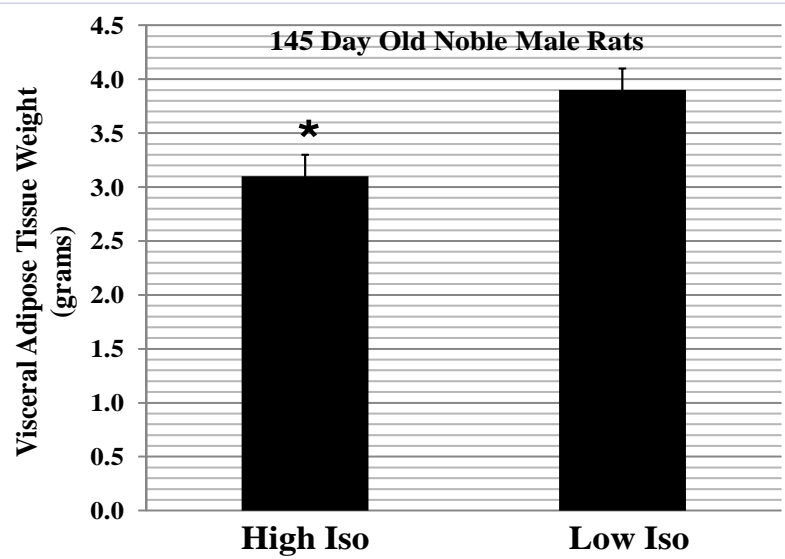

Figure 5: High Isoflavone (High-Iso) versus Low Isoflavone (Low-Iso) lifelong dietary consumption in male noble Rats: influence on visceral adipose deposition. Symbol $\left({ }^{*}\right)$ : significantly lower visceral adipose tissue weight $(\mathrm{p}<0.027)$ in adulthood of animals fed the High-Iso diet versus animals fed the Low-Iso diet. 
example, estrogens promote the accumulation of subcutaneous fat [32] while the loss of estrogens is associated with increased visceral fat [33]through its receptors, estrogen receptor alpha $(\operatorname{ER} \alpha)$ and estrogen receptor beta (ER $\beta$ ) $[34,35]$. While ER $\alpha$ plays a major role in body weight regulation [36], ER $\beta$ functions more as a SERM in the regulation of adiposity [37]. It is known that genistein, daidzein and especially equol are selective ER $\beta$ agonists $[27,28,38]$ that may play a pivotal role in the significant VAT reduction seen in the present results.

In this manner, the link between visceral fat and chronic disease is well established, especially the connection of VAT deposition in relationship to increased cancer risk $[6,8]$. By examining the body weight and VAT reducing properties of a diet high in isoflavones may suggest that the Noble rat model might be influence by consumption of this soy-derived parameter. It is intriguing to consider whether investigators realize how important a laboratory diet may be in altering study outcomes $[39,40]$. For example, long-term exposure to an isoflavone-rich diet has been shown to enhance testicular and prostate health in Long-Evans rats [41]. Male Noble rats exposed to such an isoflavone-rich diet may alter the outcome of spontaneous and hormonal induced tumors of the reproductive tract, thus influencing cancer parameter outcomes. This hypothesis remains to be tested, but recent evidence suggests that this may be the case since equol has the potential to improved prostate health in animal and human studies $[42,43]$. Thus, further research is warranted in this important field of study.

In summary, visceral rather than generalized body fat appears to play a key role between obesity being link to cancer. The present study used the Noble rodent model that examined the influence of lifelong dietary exposure to soy-derived HighIso compounds on body weight gain and VAT weight in adult female and male animals. Body weight gain and VAT weight were significantly lower in the High-Iso vs. the Low-Iso diet treatment groups, presumably by the isoflavonoid molecules acting as SERMs especially for reductions in VAT deposition. While further research is warranted, the present findings suggest potential impact of isoflavone diets on further Noble rat studies involving spontaneous and hormone-induced tumorigenesis. Finally, the concept that consumption of plant foods as a way to reduce the risk of chronic disease and cancer is supported by the findings of the present study, particularly by isoflavonoid molecules and specifically by the polyphenolic compound, equol.

\section{Acknowledgments}

Funding was provided, in part, by a BYU LS/TTO grant 19221.

\section{References}

1. Obesity: preventing and managing the global epidemic. Report of a WHO consultation (2000) World Health Organ Tech Rep Ser 894 $1-253$.

2. Flegal KM, Carroll MD, Kit BK, Ogden CL (2012) Prevalence of obesity and trends in the distribution of body mass index among us adults. JAMA 307(5): 491-497.

3. Arem H, Irwin ML (2013) Obesity and endometrial cancer survival: systemic review. Int J Obes (Lond) 37(5): 634-639.

4. Gilbert CA, Slingerland JM (2013) Cytokines, obesity, and cancer: new insights on mechanisms linking obesity to cancer risk and progression. Annu Rev Med 64(1): 45-57.

5. Ma Y, Yang Y, Wang F, Zhang P, Shi C, et al. (2013) Obesity and risk of colorectal cancer: a systematic review of prospective studies. PLOS One 8(1): e53916.

6. Vangsuvanh R, George J, Qiao L, van der Poorten D (2013) Visceral adiposity in gastrointestinal and hepatic carcinogenesis. Cancer Lett 330(1): 1-10.

7. Teucher B, Rohrmann S, Kaaks R (2010) Obesity: Focus on all-cause mortality and cancer. Maturitas 65(2): 112-116.

8. Donohoe C, Doyle SL, Reynolds JV (2011) Visceral adiposity, insulin resistance and cancer risk. Diabetology Metab Syndrome 3(12): 1-13.

9. King B, Jiang Y, Su X, Xu J, Xie L, et al. (2013) Weight control, endocrine hormones and cancer prevention. Exp Biol Med (Maywood) 238(5): 502-508.

10. Brown LM, Clegg DJ (2010) Central effects of estradiol in the regulation of food intake, body weight, and adiposity. J Steroid Biochem Mol Biol 112(1-3): 65-73.

11. He Z, Feng GS (2013) Control of body weight versus tumorigenesis by concerted action of leptin and estrogen. Rev Endocr Metab Disord 14(4): 339-345.

12. Simpson ER, Brown KA (2013) Minireview: Obesity and Breast Cancer: A tale of inflammation and dysregulated metabolism. Mol Endocrinol 27(5): 715-725.

13. Kheterpal E, Sammon JD, Diaz M, Bhandari A, Trinh QD, et al. (2013) Effect of metabolic syndrome on pathologic features of prostate cancer. Urol Oncol 31(7): 1054-1059.

14. Martin C, Zhang Y, Tonelli C, Petroni K (2013) Plants, diet, and health. Annu Rev Plant Biol 64(1): 19-46.

15.Vij U, Kumar A (2004) Phyto-estrogens and prostatic growth. Natl Med J India 17 (1): 22-26.

16. Griffiths K, Denis L, Turkes A, Morton MS (1998) Phytoestrogens and diseases of the prostate gland. Bailleres Clin Endocr 12(4): 625-647.

17.Adlercreutz H, Mazur W (1997) Phyto-estrogens, western diseases. Ann Med 29 (2): 95-120.

18. Lephart ED (2013a) Isoflavones, prenatal exposure to equol. In: Preedy VR (Ed.), Isoflavones: chemistry, analysis, function, effects, the royal society of chemistry: Thomas Graham House, Cambridge, UK, pp. 480-499.

19. Blake C, Fabick KM, Setchell KD, Lund TD, Lephart ED (2011) Neuromodulation by soy diet or equol: anti-depressive \& anti-obesitylike influences, age- \& hormone-dependent effects. BMC Neurosci 12: 28.

20. Lephart ED, Porter JP, Lund TD, Bu L, Setchell KD, et al. (2004) Dietary isoflavones alter regulatory behaviors, metabolic hormones, neuroendocrine function in long-evans rats. Nutr Metab (Lond) 1: 16.

21.Lund TD, Munson DJ, Adlercreutz H, Handa RJ, Lephart ED (2004) Androgen receptor expression in the rat prostate is down regulated by dietary phytoestrogens. Reprod Biol Endocrinol 2(5): 1-5.

22. Christov KT, Moon RC, Lantvit DD, Boone CW, kelloff GJ, et al (2004) Prostate intraepithelial neoplasia in noble rats, a potential 
intermediate endpoint for chemoprotection studies. European J Cancer 40(9): 1401-1411.

23. Cheung SY, Yuen MT, Choi HL, Cheng HK, Huang Y, et al. (2003) An expression study of hormone receptors in spontaneously developed, carcinogen-induced, hormonal-induced mammary tumors in female noble rats. Int J Oncol 22(6): 1383-1395.

24. Pollard M, Wolter WR, Sun L (2000) Prostate-seminal vesicle cancers induced in noble rats. Prostate 43(1): 71-74.

25.Xie B, Tsao SW, Wong YC (1999) Sex hormone-induced mammary carcinogenesis in female noble rats: the role of androgens. Carcinogenesis 20(8): 1597-1606.

26. Quiner TE, Nakken HL, Mason BA, Lephart ED, Hancock CR, et al. (2011) Soy content of basal diets determines the effects of supplemental selenium in male mice. J Nutr 141(12): 2159-2165.

27. Setchell KD, Brown NM, Lydeking-Olsen E (2002) The clinical importance of the metabolite equol- a clue to the effectives of soy and its isoflavones. J Nutr 132(12): 3577-3584.

28. Setchell KD, Clerici C, Lephart ED, Cole S, Heenan C, et al. (2005) $\mathrm{S}$-equol, a potent ligand for estrogen receptor beta, is the exclusive enantiomeric form of the soy isoflavone metabolite produced by human intestinal bacterial flora. Am J Clin Nutr 81(5): 1072-1079.

29. Lephart ED, Setchell KD, Handa RJ, Lund TD (2004) Behavioral effects of endocrine-disrupting substances: phytoestrogens. ILAR J 45(4): 443-454.

30. Behloul N, Wu G (2013) Genistein: a promising therapeutic agent for obesity and diabetes treatment. Eur J Pharmcol 698(1-3): 31-38.

31. Rachon D, Vortherms T, Seidlova-Wuttke D, Wuttke W (2007) Effects of dietary equol on body weight gain, intra-abdominal fat accumulation, plasma lipids, and glucose tolerance in ovariectomized sprague-dawley rats. Menopause 14(5): 925-932.

32. Krotkiewski M, Bjorntorp P, Sjostrom L, Smith U (1983) Impact of obesity on metabolism in men and women. Importance of regional adipose tissue distribution. J Clin Invest 72(3): 1150-1162.

33. Bouchard C, Despres JP, Mauriege P (1993) Genetic and nongenetic determinants of regional fat distribution. Endocr Rev 14(1): 72-93.

34. Matelski H, Greene R, Huberman M, Lokich J, Zipoli T (1985) Randomized trial of estrogen vs. tamoxifen therapy for advanced breast cancer. Am J Clin Oncol 8(2): 128-133.

35. Kuiper GG, Enmark E, Pelto-Huikko M, Nilsson S, Gustafsson JA (1996) Cloning of a novel receptor expressed in rat prostate and ovary. Proc Natl Acad Sci U S A 93(12): 5925-5930.

36. Musatov S, Chen W, Pfaff DW, Mobbs CV, Yang XJ, et al. (2007) Silencing of estrogen receptor alpha in the ventromedial nucleus of hypothalamus leads to metabolic syndrome. Proc Natl Acad Sci U S A 104(7): 2501-2506.

37. Schomberg DW, Couse JF, Mukherjee A, Lubahn DB, Sar M, et al. (1999) Targeted disruption of the estrogen receptor alpha gene in female mice: characterization of ovarian responses and phenotype in the adult. Endocr 140(6): 2733-2744.

38. Setchell KD, Clerici C (2010) Equol: history, chemistry, and formation. J Nutr 140(7): 1355S-1362S.

39. Thigpen JE, Setchell KD, Kissling GE, Locklear J, Caviness GF, et al. (2013) The estrogenic content of rodent diets, bedding, cages, and water bottles and its effect on bisphenol a studies. J Am Assoc Lab Anim Sci 52(2): 130-141.

40. Brown NM, Setchell KD (2001) Animal models impacted by phytoestrogens in commercial chow: implications for pathways influenced by hormones. Lab Invest 81(5): 735-747.

41. Blake C, Hansen T, Simmons TC, Lephart ED (2013) Long time exposure to soy/isoflavone-rich diet enhances testicular, prostate health in long-evans rats. J functional foods 5(3): 1494-1501.

42. Lund TD, Blake C, Bu L, Hamaker AN, Lephart ED (2011) Equol an isoflavonid: potential for improved prostate health, in vitro, in vivo evidence. Reprod Biol Endocrinol 9(4): 1-9.

43. Lephart ED (2013b) Severe and moderate BPH symptoms in mid-aged men improved with isoflavonoid-equol treatment: pilot intervention study. Open J Urology 3(1): 2013 